\title{
Congenital Diaphragmatic Hernia in an Adult Presenting With lleus: A Case Report
}

\author{
Ilhan Paltaci ${ }^{\mathrm{a}, \mathrm{c}}$, Muhyittin Temiz ${ }^{\mathrm{b}}$, Aydin Kaplan ${ }^{\mathrm{b}}$, Ugras Daban $^{\mathrm{b}}$, Erhan Kizilkaya ${ }^{\mathrm{b}}$
}

\begin{abstract}
Congenital diaphragmatic hernias (CDHs) are commonly diagnosed in the newborn period. Late symptomatic hernias usually develop on the basis of trauma. In this case, a 44-year-old female patient with Bochdalek hernia who did not have a history of trauma and who applied with vomiting and abdominal pain is presented.
\end{abstract}

Keywords: Congenital diaphragmatic hernia; Surgery; Adult

\section{Introduction}

Congenital diaphragmatic hernia $(\mathrm{CDH})$ is a congenital disease characterized with the displacement of abdominal organs into the thorax through a defect in diaphragm [1]. They are classified as Bochdalek, Morgagni and esophageal hernias. The most common type is the Bochdalek hernia that is localized left posteriolaterally in $80-90 \%$ of cases. It manifests with tachypnea, cyanosis and respiratory failure in the newborn and early infancy period. It is rarely seen in older ages. Diaphragmatic hernias seen in adults are commonly due to trauma [2]. In our case, a diaphragmatic hernia, without a history of trauma, causing ileus is presented.

\section{Case Report}

A 44-year-old female patient was admitted to Mustafa Ke-

\footnotetext{
Manuscript accepted for publication February 11, 2014

${ }^{a}$ General Surgery Clinic, Kutahya Gediz State Hospital, Kutahya, Turkey

${ }^{\mathrm{b}}$ General Surgery Department, Mustafa Kemal University School of Medicine, Hatay, Turkey

${ }^{\mathrm{c} C}$ Corresponding author: Ilhan Paltaci, General Surgery Clinic, Gediz

State Hospital, Turkey. Email: i.paltaci@hotmail.com

doi: http://dx.doi.org/10.14740/jmc1697w
}

mal University, Faculty of Medicine emergency service with complaints of abdominal pain, vomiting and inability to pass gas. The patient had no history of trauma and her personal and family histories were unremarkable. In the physical examination, there was abdominal distention and diffuse sensitivity; in the respiratory system examination, bowel sounds were heard in the left hemi thorax. There were no abnormal findings in laboratory parameters. In the chest X-ray, bowel loops forming air fluid levels were seen in the left hemi thorax (Fig. 1). In thorax and abdominal tomography, the stomach, spleen and bowel loops were seen in the left hemi thorax (Fig. 2). The patient was taken to surgery under emergency conditions and the abdomen was entered with a midline incision. The stomach, transverse colon, small intestines and spleen were observed to have been displaced into the thorax through a left posteriolateral $8 \mathrm{~cm}$ defect in the diaphragm. There was no evidence of organ ischemia. The organs were appropriately placed into the abdomen. The left defect on the diaphragm was primarily repaired. A thoracic tube was inserted to the left side. No postoperative complications developed and the thoracic tube was removed on the eighth day. The control standing thoracic and abdominal radiographs were evaluated as being normal. The patient was discharged

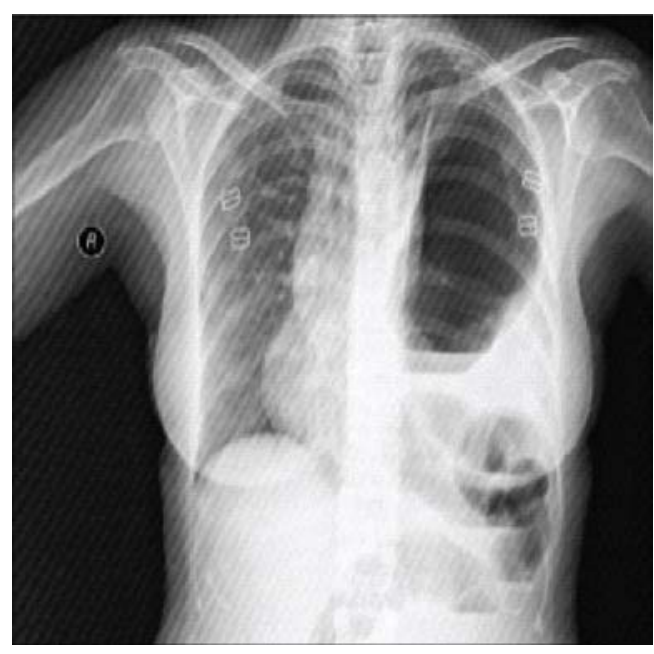

Figure 1. Intestinal loop on the left in chest X-ray. 


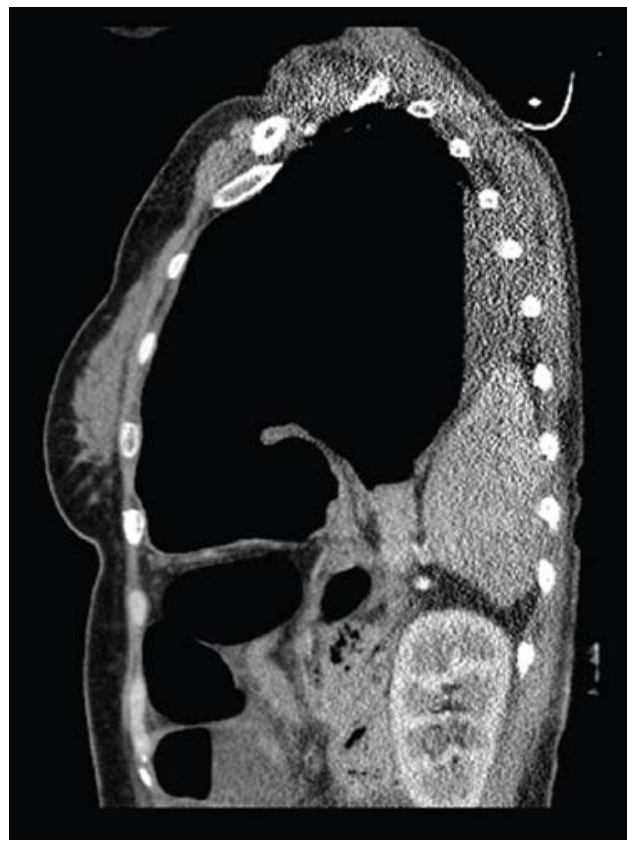

Figure 2. Spleen tissue in the thorax.

on the postoperative 12th day without any problems.

\section{Discussion and Conclusion}

The diaphragm is an organ of muscle and tendon structure that separates the thoracic and abdominal cavities. Besides the three normal foramen that allow the passage of the esophagus, aorta and the inferior vena cava, it includes two symmetrical potentially weak areas called Morgagni on the anterior and Bochdalek on the posterior aspect [3]. Delayed occurrences of Bochdalek hernia are commonly seen in right sided defects. The liver partially closes the defect on the right side. In late onset Bochdalek hernias, complaints such as pulmonary infections, vomiting, dyspnea, abdominal pain and anorexia are observed $[4,5]$. In the $\mathrm{CDH}$ serials of Berman et al conducted with 26 patients with late symptoms, primary diagnosis in 16 of the patients was reported as primary pulmonary abnormalities of which four were resolved with thoracentesis [6]. Most adult Bochdalek hernias remain asymptomatic. For this reason, it is difficult to diagnose. The patients commonly admit with chest pain and intestinal complaints [7]. Physical strain, trauma, heavy exercise, severe straining and childbirth can cause asymptomatic Bochdalek hernias to become symptomatic [8]. In our case, the patient had applied with intestinal symptoms such as abdominal pain, vomiting and inability to pass gas.

Direct chest and abdominal X-rays, barium enema examinations, ultrasonography, computerized tomography, magnetic resonances, laparoscopy and laparotomy can be used for diagnosis. The most commonly used examination is sectional computerized tomography $[9,10]$. In our case, diagnosis was suspected with direct X-rays and supported with computerized tomography. In our case, hearing bowel sounds in physical examination at the left hemithorax were suggestive of diaphragmatic hernia. Since the probability of complication development is high in cases presenting with the herniation of abdominal viscera, surgery should be scheduled without losing any time. Thoracotomy or laparotomies are appropriate interventions. We preferred laparotomy with midline incision in our case. The aim of surgery should be replacing the herniated viscera to their anatomic localizations and defect repair with the appropriate technique. The repair technique may differ according to the size and localization of the defect. Small defects can be closed primarily with nonabsorbable sutures. The performed repair should not be too taut. Prosthetic mesh should be used in larger defects that cannot be closed primarily [11].

In conclusion, although most $\mathrm{CDHs}$ are symptomatic during the newborn period, they can rarely remain asymptomatic until adulthood. Adult patients commonly admit with respiratory and intestinal complaints. Diagnosed patients should receive surgery as soon as possible. In our case, the localization of the defect and the absence of a history of trauma in the presence of clinical and radiological findings supported the diagnosis of Bochdalek hernia.

\section{References}

1. Mullins ME, Stein J, Saini SS, Mueller PR. Prevalence of incidental Bochdalek's hernia in a large adult population. AJR Am J Roentgenol. 2001;177(2):363-366.

2. Snyder WH, Jr., Greaney EM, Jr. Congenital Diaphragmatic Hernia; 77 Consecutive Cases. Surgery. 1965;57:576-588.

3. Buyukbese MA, Korman U, Erk M. Akcigergrafisindehidropnomotoraksitaklitedenbochdalekhernisi: Olgusunumu. Bilgisayarli Tomografi Bulteni. 1997;4:251254.

4. Radin DR, Ray MJ, Halls JM. Strangulated diaphragmatic hernia with pneumothorax due to colopleural fistula. AJR Am J Roentgenol. 1986;146(2):321-322.

5. Payne JH, Jr., Yellin AE. Traumatic diaphragmatic hernia. Arch Surg. 1982;117(1):18-24.

6. Booker PD, Meerstadt PW, Bush GH. Congenital diaphragmatic hernia in the older child. Arch Dis Child. 1981;56(4):253-257.

7. Batts S, Thompson MW, Person DA. Late presentation of diaphragmatic hernia in a Pacific Island pediatric population. Hawaii Med J. 2009;68(3):59-61.

8. Baglaj M, Dorobisz U. Late-presenting congenital diaphragmatic hernia in children: a literature review. Pediatr Radiol. 2005;35(5):478-488.

9. Eren S, Ciris F. Diaphragmatic hernia: diagnostic ap- 
proaches with review of the literature. Eur J Radiol. 2005;54(3):448-459.

10. Muzzafar S, Swischuk LE, Jadhav SP. Radiographic findings in late-presenting congenital diaphragmatic hernia: helpful imaging findings. Pediatr Radiol.
2012;42(3):337-342.

11. Kholdebarin R, Iwasiow BM, Keijzer R. Pulmonary development considerations in the surgical management of congenital diaphragmatic hernia. Early Hum Dev. 2011;87(11):755-758. 